\title{
A Super (A,D)-Bm-Antimagic Total Covering Of Ageneralized Amalgamation Of Fan Graphs
}

\author{
Ika Hesti Agustin 1,3, Dafik1,2 , Siti Latifah³ ${ }^{\text {, Rafiantika Megahnia Prihandini }}{ }^{3}$ \\ ${ }^{1}$ CGANT - University of Jember \\ ${ }^{2}$ Mathematics Edu. Depart. University of Jember Indonesia \\ ${ }^{3}$ Mathematics Depart. University of Jember Indonesia
}

Email: ikahesti.fmipa@unej.ac.id, d.dafik@unej.ac.id

\begin{abstract}
We assume finite, simple and undirected graphs in this study. Let $G, H$ be two graphs. By an $(a, d)-H-$ antimagic total graph, we mean any obtained bijective function $f: V(G) \cup E(G) \rightarrow\{1,2,3, \ldots,|V(G)|+$ $|E(G)|\}$ such that for each subgraph $H^{\prime}$ which is isomorphic to $H$, their total $H$-weights $w(H)=$ $\sum_{v \in E\left(H^{\prime}\right)} f(v)+\sum_{v \in E\left(H^{\prime}\right)} f(e)$ show an arithmetic sequence $\{a, a+d, a+2 d, \ldots, a+(m-1) d\}$ where $a, d$ $>0$ are integers and $m$ is the cardinality of all subgraphs $H^{\prime}$ isomorphic to $H$. An $(a, d)$ - $H$-antimagic total labeling $f$ is called super if the smallest labels are assigned in the vertices. In this paper, we will study a super $(a, d)$ - $B_{m}$-antimagicness of a connected and disconnected generalized amalgamation of fan graphs in which a path is a terminal.
\end{abstract}

Keywords: Super $(a, d)$ - $B m$-antimagic total covering, generalized amalgamation of fan graphs, connected and disconnected

\section{INTRODUCTION}

In [1], Dafik et.al. defined an amalgamation of graphs as follows: Let $G_{i}$ be a finite collection of graphs and suppose each $G_{i}$ has a fixed vertex $v_{j}$ called a terminal. The amalgamation $G_{i}$ where $v_{j}$ as a terminal is formed by taking all the $G_{i}$ 's and identifying their terminal. When $G_{i}$ are all isomorphic connected graphs, for any positive integer $m$, we denote such amalgamation by $\operatorname{Amal}(G, m)$, where $m$ denotes the number of copies of $G$. If we replace the terminal vertex $v_{j}$ by a subgraph $P \subset G$ then such amalgamation is said to be a generalized amalgamation of $G$ and denoted by $\operatorname{amal}(G, P, m)$.

Furthermore, Baca et. al. in [2] and Dafik et, el. [3] defined an $(a, d)$-edge-antimagic total labeling of $G$ as a mapping $f: V(G) \cup E(G) \rightarrow\{1,2,3, \ldots,|V(G)|+|E(G)|\}$, such that the set of edge-weights $\{f(u)+f(u v)+f(v) \mid u v \in E(G)\}$ is equal to the set $\{a, a+$ $d, a+2 d, \ldots, a+(|E(G)|-1) d\}$ for some positive integers $a$ and $d$. Combining the two previous labelings, [1], [4], [5], [6], [7] introduced the $(a, d)-H$ - antimagic total labeling. A graph $G$ is said to be an $(a, d)$ - $H$-antimagic total graph if there exist a bijective function $f$ : $V(G) \cup E(G) \rightarrow\{1,2,3, \ldots,|V(G)|+|E(G)|\}$ such that for all subgraphs $H^{\prime}$ isomorphic to $H$, the total $H$-weights $w(H)=\sum_{v \in E\left(H^{\prime}\right)} f(v)+\sum_{v \in E\left(H^{\prime}\right)} f(e)=\gamma$ form an arithmetic 
progression $\{a, a+d, a+2 d, \ldots, a+(m-1) d\}$, where $a, d>0$ are integers and $m$ is the number of all subgraphs $H^{\prime}$ isomorphic to $H$. An $(a, d)$ - $H$-antimagic total labeling $f$ is called super if the smallest labels are assigned in the vertices.

There are many results show the existence of the $(a, d)$ - $H$-antimagic total labeling, see [1], [4], [7], [8], [9], and [10]. In this paper, we will study a super $(a, d)-B_{m}$ antimagicness of an amalgamation of fans of order $m$ when a path of order $n$ is a terminal, denoted by $\operatorname{Amal}\left(F_{n}, P_{n}, m\right)$ as well as the disjoint union of multiple $s$ copies of $\operatorname{Amal}\left(F_{n}, P_{n}\right.$, $m$ ). The cover $H^{\prime}$ is a book of order two, thus $H=B_{m}$. In other word, we will show the existence of super $(a, d)$ - $B_{m}$-antimagic total labeling of $\operatorname{Amal}\left(F_{n}, P_{n}, m\right)$ and disjoint union of multiple $s$ copies of $\operatorname{Amal}\left(F_{n}, P_{n}, m\right)$ denoted by $\operatorname{simal}\left(F_{n}, P_{n}, m\right)$.

\section{LITERATURE REVIEW}

Prior to showing the research result on the existence of super $(a, d)$ - $B_{m}$-antimagic total labeling $\operatorname{simal}\left(F_{n}, P_{n}, m\right)$, we will rewrite a known lemma excluding the proof that will be useful for determining the necessary condition for a graph to be super $(\mathrm{a}, \mathrm{d})-B_{m^{-}}$ antimagic total labeling. This lemma proved by [2] provides an upper bound for feasible value of $d$, and it is a sharp.

Lemma1. [2] Let $G$ be a simple graph of order $p_{G}$ and size $q_{G}$. If $G$ is $\operatorname{super}(a, d)$-H-antimagic total labeling then $d \leq \frac{\left(p_{G}-p_{H^{\prime}}\right) p_{H^{\prime}}+\left(q_{G^{-}}-q_{H^{\prime}}\right) q_{H^{\prime}}}{t-1}$, for $H^{\prime}$ are subgraphs isomorphic to $H$. $|V(G)|=p_{G},|E(G)|=q_{G},\left|V\left(H^{\prime}\right)\right|=p_{H^{\prime}},\left|E\left(H^{\prime}\right)\right|=q_{H^{\prime}}$, and $t=\left|H_{j}^{\prime}\right|$.

\section{RESULTS AND DISCUSSIONS}

The Connected Graph. An amalgamation of fan graphs, denoted by $\operatorname{Amal}\left(F_{n}, P_{n}, m\right)$, is a connected graph with vertex set $V\left(\operatorname{Amal}\left(F_{n}, P_{n}, m\right)\right)=\left\{A_{j}, x_{i} ; 1 \leq j \leq m, 1 \leq i \leq n\right\}$ and $E\left(\operatorname{Amal}\left(F_{n}, P_{n}, m\right)\right)=\left\{A_{j}, x_{i} ; 1 \leq j \leq m, 1 \leq i \leq n\right\} \cup\left\{x_{i} x_{i+1} ; 1 \leq i \leq n-1\right\}$. Since we study a super $(a, d)-H$ - antimagic total labeling for $H^{\prime}=B_{m}$ isomorphic to $H$, thus $p_{G}=\mid V$ $\left(\operatorname{Amal}\left(F_{n}, P_{n}, m\right)\right)\left|=m+n, q_{G}=\right| E\left(\operatorname{Amal}\left(F_{n}, P_{n}, m\right)\right)\left|=m n+n-1, p_{H^{\prime}}=\right| V\left(B_{m}\right) \mid=m+2, q_{H^{\prime}}$ $=\left|E\left(B_{m}\right)\right|=2 m+1, t=\left|H_{j}^{\prime}\right|=\left|B_{m}\right|=n-1$.

If amalgamation of fan graphs $\operatorname{Amal}\left(F_{n}, P_{n}, m\right)$ has a super $(a, d)-B_{m}$ - antimagic total labeling then for $p_{G}=\left|V\left(\operatorname{Amal}\left(F_{n}, P_{n}, m\right)\right)\right|=m+n, q_{G}=\left|E\left(\operatorname{Amal}\left(F_{n}, P_{n}, m\right)\right)\right|=m n+n-1, p_{H^{\prime}}=$ $\left|V\left(F_{n}, P_{n}, m\right)\right|=m+2, q_{H^{\prime}}=\left|E\left(F_{n}, P_{n}, m\right)\right|=2 m+1, t=\left|H_{j}^{\prime}\right|=n-1$, it follows from Lemma 1.1 the upper bound of $d \leq 2 m^{2}+4 m+3$.

Now we start to describe the result of the super $(a, d)$ - $H$-antimagic total labeling of amalgamation of fan graph with the following theorems. Figure. 1 shows an illustrasion of graph $\operatorname{Amal}\left(F_{n}, P_{n}, m\right)$.

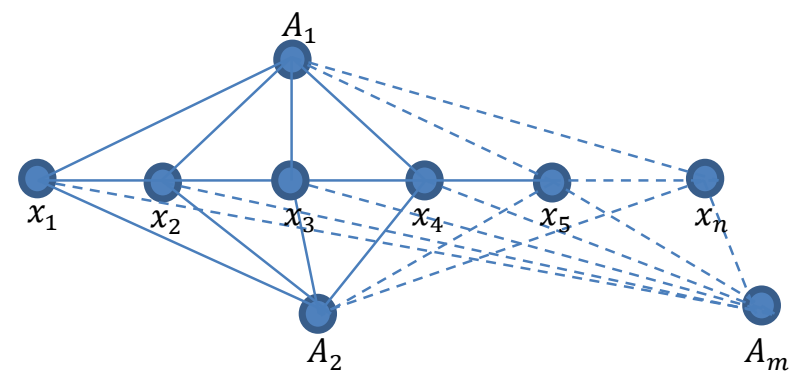

Figure. 1 illustrasion of graph $\operatorname{Amal}\left(F_{n}, P_{n}, m\right)$ 
Theorem 2.1. For $m, n \geq 2$, the graph $\operatorname{Amal}\left(F_{n}, P_{n}, m\right)$ admits a super $\left(\left(n+\frac{5}{2}\right) m^{2}+\right.$ $\left.\left(2 n+\frac{9}{2}\right) m+n+2 m+3+1,2 m+3\right)$-Bm-antimagic total labeling.

Proof. For $G=\operatorname{Amal}\left(F_{n}, P_{n}, m\right)$, define the vertex labeling $f_{1}$, as follow: $f_{1}\left(A_{j}\right)=j$ and $f_{1}\left(x_{i}\right)=m+i ; 1 \leq j \leq m, 1 \leq i \leq n$, and the edge labeling as follows:

$$
\begin{gathered}
f_{1}\left(A_{j} x_{i}\right)=m+n+(j-1) n+i ; 1 \leq j \leq m, 1 \leq i \leq n \\
f_{1}\left(x_{i} x_{i+1}\right)=m+n+n m+i+i ; 1 \leq i \leq n-1
\end{gathered}
$$

The vertex and edge labelings $f_{1}$ are a bijective function $f_{1}: V(G) \cup E(G) \rightarrow$ $\{1,2,3, \ldots, 3 m n-m+1\}$. The $H$-weights of $\operatorname{Amal}\left(F_{n}, P_{n}, m\right)$, for $1 \leq j \leq m, 1 \leq i \leq n$ under the labeling $f_{1}$, constitute the following sets $w_{f_{1}}=\bigcup_{i=1}^{n-1}\left\{f_{1}\left(A_{j}\right)+f_{1}\left(x_{i}\right)\right\}=\left\{\bigcup_{i=1}^{n-1}\{(2 m+\right.$ $\left.2 i+1+\left(\frac{m^{2}+m}{2}\right)\right\}$, and the total $H$-weights of $\operatorname{Amal}\left(F_{n}, P_{n}, m\right)$ constitute the following sets $W_{f_{1}}=\bigcup_{i=1}^{n-1}\left\{w_{f_{1}}+\sum_{j=1}^{m} f_{1}\left(A_{j} x_{i}\right)+f_{1}\left(x_{i} x_{i+1}\right)\right\}=\bigcup_{i=1}^{n-1}\left\{\left(n+\frac{5}{2}\right) m^{2}+\left(2 n+\frac{9}{2}\right) m+n+\right.$ $(2 m+3) i+1\}$. It is easy to observe that the set $W f_{1}=\left\{\left(n+\frac{5}{2}\right) m^{2}+\left(2 n+\frac{9}{2}\right) m+n+\right.$ $(2 m+4),\left(n+\frac{5}{2}\right) m^{2}+\left(2 n+\frac{9}{2}\right) m+n+4 m+7,\left(n+\frac{5}{2}\right) m^{2}+\left(2 n+\frac{9}{2}\right) m+n+6 m+$ $\left.10, \ldots,\left(n+\frac{5}{2}\right) m^{2}+\left(4 n+\frac{5}{2}\right) m+4 n-2\right\}$. It gives the desired proof.

Theorem 2.2. For $m, n \geq 2$, the graph $\operatorname{Amal}\left(F_{n}, P_{n}, m\right)$ admits a super $\left(\left(n+\frac{5}{2}\right) m^{2}+\right.$ $\left.\left(2 n+\frac{5}{2}\right) m+2 n+2,2 m+1\right)$-Bm-antimagic total labeling.

Proof. For $G=\operatorname{Amal}\left(F_{n}, P_{n}, m\right)$, define the vertex labeling $f_{2}$, as follow: $f_{2}\left(A_{j}\right)=\{n+j ; 1 \leq$ $j \leq m\}$ and $f_{2}\left(x_{i}\right)=i ; 1 \leq i \leq n$, and the edge labeling as follows:

$$
\begin{gathered}
f_{2}\left(A_{j} x_{i}\right)=2 n+m-1+(j-1) n+i ; 1 \leq j \leq m, 1 \leq i \leq n \\
f_{2}\left(x_{i} x_{i+1}\right)=2 n+m-i ; 1 \leq i \leq n-1
\end{gathered}
$$

The vertex and edge labelings $f_{2}$ are a bijective function $f_{2}: V(G) \cup E(G) \rightarrow$ $\{1,2,3, \ldots, 3 m n-m+1\}$. The $H$-weights of $\operatorname{Amal}\left(F_{n}, P_{n}, m\right)$, for $1 \leq j \leq m, 1 \leq i \leq n$ under the labeling $f_{2}$, constitute the following sets $w_{f_{2}}=\bigcup_{i=1}^{n-1}\left\{f_{2}\left(x_{i}\right)+f_{2}\left(x_{i+1}\right)+\right.$ $\left.\sum_{j=1}^{m} f_{2}\left(A_{j}\right)\right\}=\left\{\bigcup_{i=1}^{n-1}\left\{\frac{1}{2} m^{2}+j+1\right\}\right.$, and the total $H$-weights of $\operatorname{Amal}\left(F_{n}, P_{n}, m\right)$ constitute the following sets $W_{f_{2}}=\bigcup_{i=1}^{n-1}\left\{w_{f_{2}}+\sum_{j=1}^{m} f_{2}\left(A_{j}\right)+f_{2}\left(x_{i} x_{i+1}\right)\right\}=\bigcup_{i=1}^{n-1}\left\{\left(n+\frac{5}{2}\right) m^{2}+\right.$ $\left.4 n m+\frac{1}{2} m+2 n+1+i(2 m+1)\right\}$. It is easy to observe that the set $W_{f_{2}}=\left\{\left(n+\frac{5}{2}\right) m^{2}+\right.$ $\left(4 n+\frac{5}{2}\right) m+2 n+2,\left(n+\frac{5}{2}\right) m^{2}+\left(4 n+\frac{9}{2}\right) m+2 n+3,\left(n+\frac{5}{2}\right) m^{2}+\left(4 n+\frac{13}{2}\right) m+$ $\left.2 n+4, \ldots,\left(n+\frac{5}{2}\right) m^{2}+\left(6 n-\frac{3}{2}\right) m+3 n\right\}$. Therefore, the graph $\operatorname{Amal}\left(F_{n}, P_{n}, m\right)$ admits a super $\left(\left(n+\frac{5}{2}\right) m^{2}+\left(2 n+\frac{5}{2}\right) m+2 n+2,2 m+1\right)-B_{m}-$ antimagic total labeling, For $m, n \geq 2$

Theorem 2.3. For $m, n \geq 2$, the graph $\operatorname{Amal}\left(F_{n}, P_{n}, m\right)$ admits a super $\left(\frac{5}{2}\left(m^{2}+m\right)+4 n m+\right.$ $\left.6+2 m^{2}, 2 m^{2}+3\right)-B_{m}$-antimagic total labeling. 
Proof. For $G=\operatorname{Amal}\left(F_{n}, P_{n}, m\right)$, define the vertex labeling $f_{3}$, as follow: $f_{3}\left(A_{1}\right)=1, f_{3}\left(x_{i}\right)=$ $i+1 ; 1 \leq i \leq n$ and $f_{3}\left(x A_{j}\right)=n+j ; 2 \leq j \leq m$ and the edge labeling as follows:

$$
\begin{aligned}
& f_{3}\left(A_{j} x_{i}\right)=n+m i+j ; 1 \leq j \leq m, 1 \leq i \leq n \\
& f_{3}\left(x_{i} x_{i+1}\right)=m+n+n m+i ; 1 \leq i \leq n-1
\end{aligned}
$$

The vertex and edge labelings $f_{3}$ are a bijective function $f_{3}: V(G) \cup E(G) \rightarrow$ $\{1,2,3, \ldots, 3 m n-m+1\}$. The $H$-weights of $\operatorname{Amal}\left(F_{n}, P_{n}, m\right)$, for $1 \leq j \leq m, 1 \leq i \leq n$ under the labeling $f_{3}$, constitute the following sets $w_{f_{3}}=\bigcup_{i=1}^{n-1}\left\{\sum_{j=2}^{m} f_{3}\left(A_{j}\right)+f_{3}\left(x_{i}\right)+f_{3}\left(x_{i+1}\right)+\right.$ $\left.f_{3}\left(A_{1}\right)\right\}=\bigcup_{i=1}^{n-1}\left\{\frac{1}{2} m^{2}+\frac{1}{2} m+(m-1) n+2 i+3\right\}$, and the total $H$-weights of $\operatorname{Amal}\left(F_{n}\right.$, $\left.P_{n, m}\right)$ constitute the following sets $W_{f_{3}}=\cup_{i=1}^{n-1}\left\{w_{f_{3}}+f_{3}\left(x_{i} x_{i+1}\right)+\right.$ $\left.\sum_{j=1}^{m} f_{3}\left(A_{j} x_{i}\right)+f_{3}\left(A_{j} x_{i+1}\right)\right\}=\bigcup_{i=1}^{n-1}\left\{\frac{5}{2} m^{2}+\frac{5}{2} m+4 n m+3+\left(2 m^{2}+3\right) i\right\}$. It is easy to observe that the set $W f_{3}=\left\{\frac{5}{2}\left(m^{2}+m\right)+4 n m+2 m^{2}+6, \frac{5}{2}\left(m^{2}+m\right)+4 n m+4 m^{2}+\right.$ $\left.9, \ldots, 3 n^{2}\left(2 m-\frac{1}{2}\right)+n\left(\frac{15}{2}-6 m\right)+5 m-5\right\}$. It gives the desired proof

Theorem 2.4. For $n \geq 2$, the graph $A \operatorname{mal}\left(F_{n}, P_{n}, 2\right)$ admits a super $\left(\frac{29 n+32}{2}, 0\right)$-B2-antimagic total labeling for $n$ even and super $\left(\frac{29 n+32}{2}, 0\right)-B_{2}$-antimagic total labeling for $n$ odd.

Proof. Define the vertex and edge labeling $f_{4}$ as follows:

$$
\begin{gathered}
f_{4}(a)=1 ; f_{4}(b)=2 \\
f_{4}\left(x_{i}\right)=\left\{\begin{array}{c}
\frac{i+5}{2}, \text { for } 1 \leq i \leq n, i \text { odd } \\
\frac{n+i+4}{2}, \text { for } 1 \leq i \leq n, i \text { even, } n \text { even } \\
\frac{n+i+5}{2}, \text { for } 1 \leq i \leq n, i \text { even, } n \text { odd }
\end{array}\right. \\
f_{4}\left(x_{i} x_{i+1}\right)=2 n-i+2, \text { for } 1 \leq i \leq n-1 \\
f_{4}\left(b x_{i}\right)=2 n-i+1, \text { for } 1 \leq i \leq n \\
f_{4}\left(a x_{i}\right)=4 n-i+2, \text { for } 1 \leq i \leq n
\end{gathered}
$$

The vertex and edge labelings $f_{4}$ are a bijective function $f_{4}: V\left(\operatorname{Amal}\left(F_{n}, P_{n}, 2\right)\right) \cup$ $E\left(\operatorname{Amal}\left(F_{n}, P_{n}, 2\right)\right) \rightarrow\{1,2,3, \ldots, 4 n+1\}$. The $H$-weights of $\operatorname{Amal}\left(F_{n}, P_{n}, 2\right)$, for $1 \leq i \leq n$ under the labeling $f_{4}$, constitute the following sets $w_{f_{4}}=f_{4}(a)+f_{4}(b)+f_{4}\left(x_{i}\right)+$ $f_{4}\left(x_{i+1}\right)=\frac{n+2 i+16}{2}$, for $n$ even and $w_{f_{4}}=f_{4}(a)+f_{4}(b)+f_{4}\left(x_{i}\right)+f_{4}\left(x_{i+1}\right)=\frac{n+2 i+17}{2}$ for $n$ odd and the total $H$-weights of $\operatorname{Amal}\left(F_{n}, P_{n}, 2\right)$ constitute the following sets $W_{f_{4}}=w f_{4}+$ $f_{4}\left(x_{i} x_{i+1}\right)+f_{4}\left(b x_{i}\right)+f_{4}\left(b x_{i+1}\right)+f_{4}\left(a x_{i}\right)+f_{4}\left(a x_{i+1}\right)=\frac{29 n+32}{2}$, for $n$ even and $W_{f_{4}}=$ $w f_{4}+f_{4}\left(x_{i} x_{i+1}\right)+f_{4}\left(b x_{i}\right)+f_{4}\left(b x_{i+1}\right)+f_{4}\left(a x_{i}\right)+f_{4}\left(a x_{i+1}\right)=\frac{29 n+25}{2}$ for $n$ odd. It is easy to observe that the set $W f_{4}=\left\{\frac{29 n+32}{2}, \frac{29 n+32}{2}, \ldots, \frac{29 n+32}{2}\right\}$ for $n$ even and $W f_{4}=$ $\left\{\frac{29 n+25}{2}, \frac{29 n+25}{2}, \ldots, \frac{29 n+25}{2}\right\}$ for $n$ odd. Therefore, the graph $\operatorname{Amal}\left(F_{n}, P_{n}, 2\right)$ admits a super $\left(\frac{29 n+32}{2}, 0\right)-B_{2}$ - antimagic total labeling for $n \geq 2$ for $n$ even, and the graph $\operatorname{Amal}\left(F_{n}, P_{n}, 2\right)$ admits a super $\left(\frac{29 n+25}{2}, 0\right)-B_{2}$-antimagic total labeling for $n \geq 2$ for $n$ odd It gives the desired proof. 
Theorem 2.5. For $n \geq 2$, the graph $\operatorname{Amal}\left(F_{n}, P_{n}, 2\right)$ admits a super $(13 n+19,1)-B_{2}$ antimagic total labeling.

Proof. Define the vertex and edge labeling $f_{5}$ as follows:

$$
\begin{gathered}
f_{5}(a)=1 ; f_{5}(b)=n+2 \\
f_{5}\left(x_{i}\right)=i+2, \text { for } 1 \leq i \leq n \\
f_{5}\left(b x_{i}\right)=2 n-i+3, \text { for } 1 \leq i \leq n \\
f_{5}\left(a x_{i}\right)=2 n+i+2, \text { for } 1 \leq i \leq n \\
f_{5}\left(x_{i} x_{i+1}\right)=4 n-i+2 \text {, for } 1 \leq i \leq n-1
\end{gathered}
$$

The vertex and edge labelings $f_{5}$ are a bijective function $f_{5}: V\left(\operatorname{Amal}\left(F_{n}, P_{n}, 2\right)\right) \cup$ $E\left(\operatorname{Amal}\left(F_{n}, P_{n}, 2\right)\right) \rightarrow\{1,2,3, \ldots, 4 n+1\}$. The $H$-weights of $\operatorname{Amal}\left(F_{n}, P_{n}, 2\right)$, for $1 \leq i \leq n$ under the labeling $f_{5}$, constitute the following sets $w_{f_{5}}=f_{5}(a)+f_{5}(b)+f_{5}\left(x_{i}\right)+$ $f_{5}\left(x_{i+1}\right)=n+2 i+6$, and the total $H$-weights of $\operatorname{Amal}\left(F_{n}, P_{n}, 2\right)$ constitute the following sets $W_{f_{5}}=w f_{5}+f_{5}\left(x_{i} x_{i+1}\right)+f_{5}\left(b x_{i}\right)+f_{5}\left(b x_{i+1}\right)+f_{5}\left(a x_{i}\right)+f_{5}\left(a x_{i+1}\right)=13 n+i+18$. It is easy to observe that the set $W f_{5}=\left\{\frac{29 n+32}{2}, \frac{29 n+32}{2}, \ldots, \frac{29 n+32}{2}\right\}$ for $n$ even and $W f_{5}=$ $\{13 n+19,13 n+20, \ldots, 14 n+18\}$. Therefore, the graph $\operatorname{Amal}\left(F_{n}, P_{n}, 2\right)$ admits a super $(13 n+i+18,1)-B_{2}-$ antimagic total labeling for $n \geq 2$ It gives the desired proof

The Disconnected Graph. A disjoint union of amalgamation of fan graphs, denoted by $\operatorname{sAmal}\left(F_{n}, P_{n}, m\right)$, is a disconnected graph with vertex set $V\left(\operatorname{sAmal}\left(F_{n}, P_{n}, m\right)\right)=A_{j}^{k}, x_{i}^{k} ; 1 \leq$ $j \leq m, 1 \leq i \leq n ; 1 \leq k \leq s\}$ and $E\left(\operatorname{sAmal}\left(F_{n}, P_{n}, m\right)\right)=A_{j}^{k}, x_{i}^{k} ; 1 \leq j \leq m, 1 \leq i \leq n ; 1 \leq$ $k \leq s\}$ Since we study a super $(a, d)$ - $H$ - antimagic total labeling for $H^{\prime}=B_{m}$ isomorphic to $H$, thus $p_{G}=\left|V\left(\operatorname{sAmal}\left(F_{n}, P_{n}, m\right)\right)\right|=s(m+n), q_{G}=\left|E\left(\operatorname{sAmal}\left(F_{n}, P_{n}, m\right)\right)\right|=s(m n+n-1), p_{H^{\prime}}=$ $\left|V\left(B_{m}\right)\right|=m+2, q_{H^{\prime}}=\left|E\left(B_{m}\right)\right|=2 m+1, t=\left|H_{j}^{\prime}\right|=\left|B_{m}\right|=s(n-1)$.

If amalgamation of fan graphs $\operatorname{sAmal}\left(F_{n}, P_{n}, m\right)$ has a super $(a, d)-B_{m}$ - antimagic total labeling then for $p_{G}=s(m+n), q_{G}=s(m n+n-1), p_{H^{\prime}}=m+2, q_{H^{\prime}}=2 m+1, t=s(n-1)$, it follows from Lemma 1.1 the upper bound of

$$
d \leq \frac{\left[m^{2}(2 s n+s-5)+4 s n m+3 s n-8 m-s-5\right.}{s(n-1)-1}
$$

Theorem 2.6. For $m, n \geq 2, s \geq 2$ and $m$ is even integer, the $\operatorname{sAmal}\left(F_{n}, P_{n}, m\right)$ admits a super $\left((3+n) m^{2} s+(2 m+1) n s-2 s+\frac{m}{2}+(2 m+3)(s+1), 2 m+3\right)-B m^{-}$antimagic total labeling.

Proof. For $G=\operatorname{sAmal}\left(F_{n}, P_{n}, m\right)$, define the vertex labeling $f_{6}$, for $1 \leq j \leq m, 1 \leq i \leq n(m$ is even integer), $1 \leq k \leq s$ as follow:

$$
f_{6}\left(A_{j}^{k}\right)=\left\{\begin{array}{cl}
k+(j-1) s ; & \text { for } 1 \leq k \leq s, 1 \leq j \leq m, j \text { odd } \\
(m-4) s+1+j s-k & \text { for } 1 \leq k \leq s, 1 \leq j \leq m, j \text { even }
\end{array}\right.
$$

and edge labeling as follow:

for $1 \leq j \leq m, 1 \leq i \leq n$ ( $m$ is even integer), $1 \leq k \leq s$

for $1 \leq i \leq n-1,1 \leq k \leq s$

$$
f_{6}\left(A_{j}^{k} x_{i}^{k}\right)=s(m+n j+i-1)+k
$$

$$
f_{6}\left(x_{i}^{k} x_{i+1}^{k}\right)=s(m+n+n m+i-1)+k
$$


The vertex and edge labelings $f_{6}$ are a bijective function $f_{6}: V(G) \cup E(G) \rightarrow$ $\{1,2,3, \ldots, 3 m n s-m s+s\}$. The $H$-weights of $\operatorname{sAmal}\left(F_{n}, P_{n}, m\right)$, for $1 \leq j \leq m, 1 \leq i \leq n(m$ is even integer), $1 \leq k \leq s$ under the labeling $f_{6}$, constitute the following sets $w_{f_{6}}=$ $\bigcup_{i=1}^{n-1} \bigcup_{k=1}^{s}\left\{f_{6}\left(x_{i}^{k}\right)+f_{6}\left(x_{i+1}^{k}\right)\right\}+\sum_{j=1}^{m}\left(A_{j}^{k}\right)=\bigcup_{i=1}^{n-1} \bigcup_{k=1}^{s}\{s(2 m+2 i-1)+2 k+$ $\left.\frac{m}{2}(2 m s-4 s+1)\right\}$, and the total $H$-weights of $\operatorname{sAmal}\left(F_{n}, P_{n}, m\right)$ constitute the following sets:

$W_{f_{6}}=\cup_{i=1}^{n-1} \bigcup_{k=1}^{s}\left\{w_{f_{6}}+f_{6}\left(x_{i}^{k} x_{i+1}^{k}\right)+\sum_{j=1}^{m}\left[f_{6}\left(A_{j}^{k}\right)+f_{6}\left(A_{j}^{k} x_{i+1}^{k}\right)\right]=\bigcup_{i=1}^{n-1} \bigcup_{k=1}^{s}\{s(3 m+\right.$ $n+n m+3 i-2)+3 k+\frac{m}{2}(2 m s-4 s+1)+\sum_{j=1}^{m}[s(m+j n+i-1)+k+s(m+j n+$ $\left.i)+k]\}=\bigcup_{i=1}^{n-1} \bigcup_{k=1}^{s}\left\{(3+n) m^{2} s+(2 m+1) n s-2 s+\frac{m}{2}+(2 m+3)(s i+k)\right\}\right\}$. It is easy to observe that the set $W_{f_{6}}=\left\{(3+n) m^{2} s+(2 m+1) n s-2 s+\frac{m}{2}+(2 m+3)(s+\right.$ $1),(3+n) m^{2} s+(2 m+1) n s-2 s+\frac{m}{2}+(2 m+3)(s+2),(3+n) m^{2} s+(2 m+1) n s-$ $2 s+\frac{m}{2}+(2 m+3)(s+3), \ldots, 2 m s\left(2 n^{2}-2 n+1\right)-s\left(n^{2}-n-\frac{5}{2}\right)-\frac{1}{2}\left(n^{2}-n-3\right)+$ $\left.\left(n^{2}+2 n-3\right)(m s+s)\right\}$. It gives the desired proof.

Theorem 2.7. For $m, n \geq 2, s \geq 2$ and $m$ is even integer, the $\operatorname{sAmal}\left(F_{n}, P_{n}, m\right)$ admits a super $\left(\frac{m^{2} s}{2}(2 n+5)+(2 s n-s)(2 m+1)+\frac{m}{2}+1+(2 m+1)(s+1), 2 m+1\right)$-Bm-antimagic total labeling.

Proof. For $G=\operatorname{sAmal}\left(F_{n}, P_{n}, m\right)$, define the vertex labeling $f_{5}$, for $1 \leq j \leq m, 1 \leq i \leq n, 1 \leq$ $k \leq s$ as follow:

$$
f_{7}\left(A_{j}^{k}\right)= \begin{cases}s(j-1)+s n+k ; & \text { for } 1 \leq k \leq s, 1 \leq j \leq m, j \text { odd } \\ s n+1+j s-k & \text { for } 1 \leq k \leq s, 1 \leq j \leq m, j \text { even }\end{cases}
$$

and edge labeling as follow:

for $1 \leq j \leq m, 1 \leq i \leq n, 1 \leq k \leq s$

$$
f_{7}\left(A_{j}^{k} x_{i}^{k}\right)=s(2 n+m)+1-s i-k
$$

for $1 \leq i \leq n-1,1 \leq k \leq s$

$$
f_{7}\left(x_{i}^{k} x_{i+1}^{k}\right)=s(2 n+m-2+(j-1) n+i)+k
$$

The vertex and edge labelings $f_{7}$ are a bijective function $f_{7}: V(G) \cup E(G) \rightarrow$ $\{1,2,3, \ldots, 3 m n s-m s+s\}$. The $H$-weights of $\operatorname{sAmal}\left(F_{n}, P_{n}, m\right)$, for $1 \leq j \leq m, 1 \leq i \leq n(m$ is even integer), $1 \leq k \leq s$ under the labeling $f_{5}$, constitute the following sets $w_{f_{7}}=$ $\bigcup_{i=1}^{n-1} \bigcup_{k=1}^{s}\left\{f_{7}\left(x_{i}^{k}\right)+f_{7}\left(x_{i+1}^{k}\right)\right\}+\sum_{j=1}^{m}\left(A_{j}^{k}\right)=\bigcup_{i=1}^{n-1} \bigcup_{k=1}^{s}\left\{\frac{1}{2}\left(s m^{2}+m\right)+s(m n-1)+\right.$ $\left.2(s i+k)\}+2 k+\frac{m}{2}(2 m s-4 s+1)\right\}$, and the total $H$-weights of $\operatorname{sAmal}\left(F_{n}, P_{n}, m\right)$ constitute the following sets $W_{f_{7}}=\bigcup_{i=1}^{n-1} \bigcup_{k=1}^{s}\left\{w_{f_{7}}+f_{7}\left(x_{i}^{k} x_{i+1}^{k}\right)+\sum_{j=1}^{m}\left[f_{7}\left(A_{j}^{k}\right)+\right.\right.$ $\left.f_{5}\left(A_{j}^{k} x_{i+1}^{k}\right)\right]=\bigcup_{i=1}^{n-1} \bigcup_{k=1}^{s}\left\{\frac{m^{2} s}{2}(2 n+5)+(2 s n-s)(2 m+1)+\frac{m}{2}+1+(2 m+1)(s i+\right.$ $k)\}$. It is easy to observe that the set $W_{f_{7}}=\left\{\frac{m^{2} s}{2}(2 n+5)+(2 s n-s)(2 m+1)+\frac{m}{2}+1+\right.$ $(2 m+1)(s+1), \frac{m^{2} s}{2}(2 n+5)+(2 s n-s)(2 m+1)+\frac{m}{2}+1+(2 m+1)(s+$ $2), \frac{m^{2} s}{2}(2 n+5)+(2 s n-s)(2 m+1)+\frac{m}{2}+1+(2 m+1)(s+3), \ldots, \frac{m^{2} s}{2}(2 n+5)+$ $\left.(2 s n-s)(2 m+1)+\frac{m}{2}+1+(2 m+1) s n\right\}$. It gives the desired proof. 
Theorem 2.8. For $m, n \geq 2, s \geq 2$ and $m$ is even integer, the $\operatorname{sAmal}\left(F_{n}, P_{n}, m\right)$ admits a super $\left(\frac{5}{4} m^{2} s+s n(4 m+2)+2 s+\frac{m}{2}+2+\left(2 m^{2}-1\right) s+2 m-1,2 m-1\right)-B m$ - antimagic total labeling.

Proof. For $G=\operatorname{sAmal}\left(F_{n}, P_{n}, m\right)$, define the vertex labeling $f_{8}$, for $1 \leq j \leq m, 1 \leq i \leq n(m$ is even integer), $1 \leq k \leq s$ as follow:

$$
\begin{gathered}
f_{8}\left(A_{1}^{k}\right)=k \\
f_{8}\left(A_{j}^{k}\right)=\left\{\begin{array}{rr}
s n+1+j s-k ; & s(n+2)+1-s i-k \\
s(n+j-1)+k ; & \text { for } 1 \leq k \leq s, 1 \leq j \leq m, j \text { odd }
\end{array}\right. \\
\text { for } 1 \leq k \leq s, 1 \leq j \leq m, j \text { even }
\end{gathered}
$$

and edge labeling as follow:

for $1 \leq j \leq m, 1 \leq i \leq n$ ( $m$ is even integer), $1 \leq k \leq s$

for $1 \leq i \leq n-1,1 \leq k \leq s$

$$
f_{8}\left(A_{j}^{k} x_{i}^{k}\right)=s(n+m i+j-1)+k
$$

$$
f_{8}\left(x_{i}^{k} x_{i+1}^{k}\right)=s(n+m+n m+i-1)+k
$$

The vertex and edge labelings $f_{8}$ are a bijective function $f_{8}: V(G) \cup E(G) \rightarrow$ $\{1,2,3, \ldots, 3 m n s-m s+s\}$. The $H$-weights of $\operatorname{sAmal}\left(F_{n}, P_{n}, m\right)$, for $1 \leq j \leq m, 1 \leq i \leq n(m$ is even integer), $1 \leq k \leq s$ under the labeling $f_{8}$, constitute the following sets

$w_{f_{8}}=\bigcup_{i=1}^{n-1} \bigcup_{k=1}^{S}\left\{f_{8}\left(A_{1}^{k}\right)+f_{8}\left(x_{i}^{k}\right)+f_{8}\left(x_{i+1}^{k}\right)+\sum_{j=2}^{m} f_{8}\left(A_{j}^{k}\right)+\right.$

$\left.\sum_{j=3}^{m} f_{8}\left(A_{j}^{k}\right)\right\}=\bigcup_{i=1}^{n-1} \bigcup_{k=1}^{s}\left\{s\left(\frac{m^{2}}{2}+n-2 i+m n+3\right)+\frac{m}{2}+2-2 k\right\}$, and the total $H$ weights of $\operatorname{sAmal}\left(F_{n}, P_{n}, m\right)$ constitute the following sets $W_{f_{8}}=\bigcup_{i=1}^{n-1} \bigcup_{k=1}^{s}\left\{w_{f_{8}}+\right.$ $\left.f_{8}\left(x_{i}^{k} x_{i+1}^{k}\right)+\sum_{j=1}^{m}\left[f_{8}\left(A_{j}^{k} x_{i}^{k}\right)+f_{8}\left(A_{j}^{k} x_{i+1}^{k}\right)\right]\right\}=\bigcup_{i=1}^{n-1} \bigcup_{k=1}^{s}\left\{\frac{5}{2} m^{2} s+\operatorname{sn}(4 m+2)+2 s+\right.$ $\left.\frac{m}{2}+2+\left(2 m^{2}-1\right) s i+(2 m-1) k\right\}$. It is easy to observe that the set $W_{f_{8}}=\left\{\frac{5}{2} m^{2} s+\right.$ $s n(4 m+2)+2 s+\frac{m}{2}+2+\left(2 m^{2}-1\right) s+(2 m-1), \frac{5}{2} m^{2} s+s n(4 m+2)+2 s+\frac{m}{2}+$ $2+\left(2 m^{2}-1\right) s+4 m-2, \frac{5}{2} m^{2} s+\operatorname{sn}(4 m+2)+2 s+\frac{m}{2}+2+\left(2 m^{2}-1\right) s+6 m-$ $\left.3, \ldots, \frac{5}{2} m^{2} s+s n(4 m+2)+2 s+\frac{m}{2}+2+\left(2 m^{2}-1\right) s(n-1)+(2 m-1) s\right\}$. It gives the desired proof.

Theorem 2.9. For $n \geq 2$, the graph $\operatorname{sAmal}\left(F_{n}, P_{n}, 2\right)$ admits a super $(12 s n+16 s+5,1)$ - $B_{2}$ antimagic total labeling.

Proof. Define the vertex and edge labeling $f_{9}$ as follows:

$$
\begin{gathered}
f_{9}\left(a^{j}\right)=s-j+1, \text { for } 1 \leq j \leq s \\
f_{9}\left(b^{j}\right)=s+j, \text { for } 1 \leq j \leq s \\
f_{9}\left(x_{i}{ }^{j}\right)=s i+s+j, \text { for } 1 \leq i \leq n, 1 \leq j \leq s \\
f_{9}\left(a^{j} x_{i}^{j}\right)=2 s n+3 s-s i-j+1, \text { for } 1 \leq i \leq n, 1 \leq j \leq s \\
f_{9}\left(b^{j} x_{i}^{j}\right)=s i+2 s n+s+j, \text { for } 1 \leq i \leq n, 1 \leq j \leq s \\
f_{9}\left(x_{i}{ }^{j} x_{i+1}{ }^{j}\right)=4 s n-s i+2 s-j+1, \text { for } 1 \leq i \leq n-1,1 \leq j \leq s
\end{gathered}
$$

The vertex and edge labelings $f_{9}$ are a bijective function $f_{9}: V\left(\operatorname{simal}\left(F_{n}, P_{n}, 2\right)\right) \cup$ $E\left(\operatorname{sAmal}\left(F_{n}, P_{n}, 2\right)\right) \rightarrow\{1,2,3, \ldots, 4 s n+s\}$. The $H$-weights of $\operatorname{sAmal}\left(F_{n}, P_{n}, 2\right)$, for $1 \leq i \leq$ $n$ and $1 \leq j \leq s$ under the labeling $f_{9}$, constitute the following sets $w_{f_{9}}=f_{9}\left(a^{j}\right)+$ $f_{9}\left(b^{j}\right)+f_{9}\left(x_{i}^{j}\right)+f_{9}\left(x_{i+1}^{j}\right)=5 s+2 j+2 s i+1$, and the total $H$-weights of $\operatorname{sAmal}\left(F_{n}, P_{n}\right.$, 
2) constitute the following sets $W_{f_{9}}=w_{f_{9}}+f_{9}\left(a^{j} x_{i}^{j}\right)+f_{9}\left(a^{j} x_{i+1}^{j}\right)+f_{9}\left(b^{j} x_{i}^{j}\right)+$ $f_{9}\left(b^{j} x_{i+1}^{j}\right)+f_{9}\left(x_{i}^{j} x_{i+1}^{j}\right)=15 s+j+s i+4+12 s n$. It is easy to observe that the set $W f_{9}=\{12 s n+16 s+5,12 s n+16 s+6, \ldots, 13 s n+16 s+4\}$. Therefore, the graph $\operatorname{sAmal}\left(F_{n}, P_{n}, 2\right)$ admits a super $(12 s n+16 s+5,1)-B_{2}$ - antimagic total labeling for $m, n \geq 2$ It gives the desired proof .

Theorem 2.10. For $n \geq 2$, the graph $\operatorname{sAmal}\left(F_{n}, P_{n}, 2\right)$ admits a super $(11 s n+17 s+6,3)$ $B_{2}$-antimagic total labeling.

Proof. Define the vertex and edge labeling $f_{10}$ as follows:

$$
\begin{gathered}
f_{10}\left(a^{j}\right)=s-j+1, \text { for } 1 \leq j \leq s \\
f_{10}\left(b^{j}\right)=s+j, \text { for } 1 \leq j \leq s \\
f_{10}\left(x_{i}^{j}\right)=s i+s+j, \text { for } 1 \leq i \leq n, 1 \leq j \leq s \\
f_{10}\left(a^{j} x_{i}^{j}\right)=2 s n+3 s-s i-j+1, \text { for } 1 \leq i \leq n, 1 \leq j \leq s \\
f_{10}\left(b^{j} x_{i}^{j}\right)=s i+2 s n+s+j, \text { for } 1 \leq i \leq n, 1 \leq j \leq s \\
f_{10}\left(x_{i}^{j} x_{i+1}^{j}\right)=s i+s+3 s n+j, \text { for } 1 \leq i \leq n-1,1 \leq j \leq s
\end{gathered}
$$

The vertex and edge labelings $f_{9}$ are a bijective function $f_{10}: V\left(\operatorname{simal}\left(F_{n}, P_{n}, 2\right)\right) \cup$ $E\left(\operatorname{sAmal}\left(F_{n}, P_{n}, 2\right)\right) \rightarrow\{1,2,3, \ldots, 4 s n+s\}$. The $H$-weights of $\operatorname{sAmal}\left(F_{n}, P_{n}, 2\right)$, for $1 \leq i \leq$ $n$ and $1 \leq j \leq s$ under the labeling $f_{10}$, constitute the following sets $w_{f_{10}}=f_{10}\left(a^{j}\right)+$ $f_{10}\left(b^{j}\right)+f_{10}\left(x_{i}^{j}\right)+f_{10}\left(x_{i+1}^{j}\right)=5 s+2 j+2 s i+1$, and the total $H$-weights of $\operatorname{sAmal}\left(F_{n}\right.$, $P_{n}$, 2) constitute the following sets $W_{f_{10}}=w_{f_{10}}+f_{10}\left(a^{j} x_{i}^{j}\right)+f_{10}\left(a^{j} x_{i+1}^{j}\right)+$ $f_{10}\left(b^{j} x_{i}^{j}\right)+f_{10}\left(b^{j} x_{i+1}{ }^{j}\right)+f_{10}\left(x_{i}{ }^{j} x_{i+1}{ }^{j}\right)=3 m i+14 m+3 j+3+11 s n$. It is easy to observe that the set $W f_{10}=\{11 s n+17 s+6,11 s n+17 s+9, \ldots, 14 s n+17 s+3\}$. Therefore, the graph $\operatorname{sAmal}\left(F_{n}, P_{n}, 2\right)$ admits a super $(11 s n+17 s+6,3)-B_{2}$-antimagic total labeling for $m, n \geq 2$ It gives the desired proof.

\section{CONCLUSIONS}

In this paper, the result show that super $(a, d)$ - $B_{m}$-antimagic total labeling of $\operatorname{Amal}\left(F_{n}\right.$, $\left.P_{n}, m\right)$ and $\operatorname{sAmal}\left(F_{n}, P_{n}, m\right)$ for some feasible $d$ are respectively $d \in\{2 m+1,2 m+$ $\left.3,2 m^{3}+3\right\}$ and $d \in\{2 m+3,2 m+1,2 m-1\}$. Apart from obtained $d$ above, we haven't found any result yet, so we propose the following open problem:

Let $s G=\operatorname{sAmal}\left(F_{n}, P_{n}, m\right)$, for $m, n \geq 2, s \geq 2$, and $s$ odd, does $s G$ admit a super $(a, d)$ - $B_{m^{-}}$ antimagic total labeling for feasible d?

Acknowledgement. We gratefully acknowledge the support from DP2M HIKOM Grant and research group CGANT 2017, University of Jember, Indonesia.

\section{REFERENCES}

[1] Dafik, I. H. Agustin, and N. Khuri Faridatun, "Super (a, d)-F- imagic total labeling for a connected and disconnected amalgamation of fan graphs," in AIP Conference Proceedings, 2016, vol. 1707.

[2] M. Baca, Dafik, M. Miller, and J. Ryan, "Antimagic labeling of disjoint union of s-crowns," Util. Math., vol. 79, 2009.

[3] Dafik, M. Miller, J. Ryan, and M. Bača, “Super edge-antimagic total labelings of mKn,n,n,” Ars Comb., vol. 101, 2011.

[4] A. Semaničová-Feňovčíková, M. Bača, M. Lascsáková, M. Miller, and J. Ryan, "Wheels are CycleAntimagic," North-Holland, 2015. 
[5] S. David Laurence and K. Kathiresan, “On super (a,d)-Ph-antimagic total labeling of Stars,” AKCE Int. J. Graphs Comb., vol. 12, no. 1, pp. 54-58, 2015.

[6] Dafik, I. H. Agustin, and D. Hardiyantik, "The Connected and Disjoint Union of Semi Jahangir Graphs Admit a Cycle-Super (a, d)-Atimagic Total Labeling," J. Phys. Conf. Ser., vol. 693, no. 1, 2016.

[7] M. Matamala and J. Zamora, "Weighted antimagic labeling: an algorithmic approach," NorthHolland, 2015.

[8] M. Nalliah and M. Nalliah, "Super $(a, d)$-edge antimagic total labelings of friendship and generalized friendship graphs," North-Holland, 2015.

[9] Dafik, A. K. Purnapraja, and R. Hidayat, "Cycle-Super Antimagicness of Connected and Disconnected Tensor Product of Graphs," in Procedia Computer Science, 2015, vol. 74, pp. 93-99.

[10] Y.C. Liang, T.L. Wong, and X. Zhu, “Anti-magic labeling of trees,” Discrete Math., vol. 331, pp. 9-14, 2014. 